\title{
FEMINISMO JURÍDICO: UM CAMPO DE REFLEXÃO E AÇÃO EM PROL DO EMPODERAMENTO JURÍDICO DAS MULHERES ${ }^{1}$
}

\author{
Salete Maria da Silva ${ }^{2}$
}

Resumo: Este artigo discute o feminismo jurídico, entendido como um campo de reflexão teórica e de prática jurídica feminista. O objetivo principal é facilitar a aproximação de estudantes e profissionais do Direito com o tema em apreço, estimulando mudanças de perspectiva e ações democráticas e emancipatórias em favor das mulheres na referida seara. Trata-se do resultado de uma longa pesquisa qualitativa, de caráter bibliográfico e documental, orientada, autoetnograficamente, pela memória, trajetória, curiosidade e experiência da autora, como docente, pesquisadora e advogada feminista. Os argumentos estão distribuídos em quatro tópicos sequenciais, assim denominados: contextualizando o tema; da crítica feminista ao Direito à teoria feminista do
Direito; feminismo jurídico; empoderamento jurídico feminino, pensando, especialmente, nas mulheres oriundas das camadas populares e diversas.

Palavras-chave: Gênero. Direito. Feminismo Jurídico. Empoderamento das mulheres.

\begin{abstract}
This article discusses or legal feminism, understood as a field of theoretical reflection and feminist legal practice. The main objective is to facilitate the rapprochement of students and law professionals with this question, stimulating changes of perspective and democratic and emancipatory actions in favor of womens in the mentioned area.
\end{abstract}

\footnotetext{
${ }^{1}$ Uma primeira versão deste artigo foi apresentada durante o Seminário Internacional sobre Gênero e Direito, realizado nos dias 06 e 07 de dezembro de 2018, pela Escola da Magistratura do Estado do Rio de Janeiro - EMERJ, por iniciativa da juíza Dra. Adriana Mello. Na ocasião, fiz parte do Painel de número III, intitulado "Feminismo Jurídico e os desafios no Brasil e na América Latina", juntamente com a Profa. Dra. Isabel Jaramillo, sob a coordenação do juiz federal Roger Raupp Rios.

2 Docente do Programa de Mestrado e Doutorado em Estudos Interdisciplinares sobre Mulheres, Gênero e Feminismo-PPGNEIM/UFBA Docente do Departamento de Estudos de Gênero e Feminismo-FCCH/UFBA Coordenadora da Especialização em Educação em Gênero e Direitos Humanos. Líder do JUSFEMINA (grupo de Pesquisa em Gênero, Direito e Políticas para as Mulheres), UFBA/CNPq.
} 
It is the result of a long qualitative research, of a bibliographic and documentary nature, oriented, autoethnographically, by memory, trajetória, curiosidade and experience of the author, as a teacher, researcher and feminist advocate. The arguments are distributed in four topics sequential topics, so called: contextualizing the theme; gives a feminist critique to Right to feminist theory of law; legal feminism; feminine legal empowerment, thinking, especially, in the womens of the people and diverse litters.

Keywords: Gender. Right. Legal Feminism. Empowerment of women.

\section{Contextualizando o tema}

Após três séculos e meio de existência, o feminismo, enquanto movimento social, continua atual e necessário (Costa, 2005), notadamente nas sociedades onde se registram elevadas taxas de desigualdade de gênero e índices alarmantes de violência contra as mulheres, atingindo, sobremaneira, as negras e pobres, como é o caso do Brasil.

Mundialmente reconhecido como o movimento social mais influente do século $\mathrm{XX}$, o feminismo também invadiu o mundo da ciência (Bandeira, 2008), produzindo incômodos questionamentos e lançando luzes teóricas e metodológicas sobre diversos temas, problemas e áreas de estudo. Apesar disto, a infiltração do feminismo na seara do Direito ainda é lenta, acanhada e modesta (Silva, 2018); embora venha acontecendo, paulatinamente, nas últimas três décadas em toda a América Latina (Costa, 2014).

Esta expansão, todavia, não se dá, de maneira sistemática no âmbito das disciplinas dos cursos de Direito, mas por meio da produção teórica e do ativismo jurídico de algumas feministas comprometidas com a mudança de mentalidades e de práticas profissionais androcêntricas e sexistas na área em comento (Tovar, 2011; Silva; Wright; Nicácio, 2016). Tais iniciativas, no entanto, vem sendo denominadas - e se autodenominando - de "Pensamento Jurídico Feminista" (Costa, 2014) ou de "Teoria Feminista do Direito"(Smart, 2000; Campos, 2012), sem adotar, ao menos abertamente, a expressão "Feminismo Jurídico", utilizada raramente por algumas poucas autoras, dentre as quais eu me incluo (Silva, 2018; Lerussi, Costa, 2018; Pitch, 2010). 
Ao advogar a assunção da expressão Feminismo Jurídico, o faço desejando demarcar não apenas uma posição teórica, mas uma atitude política explícita, dentro e fora do sistema de justiça; o que, necessariamente, se faz não apenas nomeando ${ }^{3}$, mas assumindo, sem vacilo ou titubeio, aquilo que efetivamente se pretende realizar, isto é, a despatriarcalização das estruturas jurídicas e de sua cultura hegemônica que, além de androcêntrica, tem sido histórica e flagrantemente patriarcal e sexista.

Neste artigo, portanto, objetivo facilitar a aproximação entre estudantes e profissionais do Direito com o tema em

3 Adoto o entendimento de que nomear é politizar, isto é, é tornar pública a questão e, portanto, merecedora de reflexão e (re)conhecimento.

4 A autoetnografia é considerada uma abordagem teórica e metodológica, mas, sobretudo, uma forma de escrita que se constitui a partir de um diálogo entre a experiência pessoal (do/a autor/a) com o meio social em que vive, em que se forja, em que se constitui como um sujeito que reflete e atua sobre determinada realidade. Este método permite que haja uma fusão entre a narrativa pessoal e a exploração do tema em seu contexto sócio cultural. Evoca lembranças, experiências, observações e atuações, sendo algo muito comum em algumas áreas ou profissões. É um explorado por antropólogas/os, historiadoras/es, jornalistas, dentre outros, mas vai ganhando espaço no âmbito de outras ciências humanas e sociais. O Direito estaria imune? Penso que não, pois não se faz ciência apreço, haja vista a escassez bibliográfica sobre $\mathrm{o}$ assunto $\mathrm{e} \quad \mathrm{o}$ consequente déficit na educação jurídica brasileira, a começar pelas disciplinas propedêuticas das Faculdades de Direito que, em regra, passam ao largo destas reflexões, mesmo quando falam em "direitos das mulheres".

Este texto resulta de uma longa pesquisa qualitativa, de caráter bibliográfico e documental, orientada, autoetnograficamente $^{4}$, pela memória subjetiva, pela trajetória ativista, pela curiosidade científica e pela experiência jurídica, como docente, pesquisadora e advogada feminista, com mais de vinte anos de atuação neste campo ${ }^{5}$.

feminista fora de si, apartada do mundo, dos fatos, das questões que nos afetam pessoal e profissionalmente.

${ }^{5}$ Em meados da década de 1990, eu já atuava como advogada feminista, acompanhando mulheres e homossexuais em situação de violência e/ou discriminação no estado do Ceará. E em que pese ter recebido, assim como todo mundo, uma formação jurídica insensível ao gênero, busquei, autodidaticamente, suprir esta carência, estimulada pela militância política e pela atuação profissional à época. Consolidei minha aproximação teórica com o campo feminista e o pluralismo jurídico durante o mestrado em Direito e o doutorado em estudos de gênero. Ao longo da jornada, ajudei a fundar duas associações LGBT no Cariri cearense e atuei em diversos casos de violência contra a mulher, fazendo audiências e júris populares, tendo atuado como "defensora pública" dativa, durante quase uma década na comarca de Caririaçu. 
Nos tópicos que se seguem, apresento, primeiramente, as críticas feministas ao campo jurídico e a paulatina construção de uma teoria feminista do Direito para, após, introduzir o tema/conceito Feminismo jurídico, advogando sua adoção explícita por parte das feministas que atuam nesta seara. Feito isto, trato também do empoderamento jurídico feminino, pensando, especialmente, nas mulheres oriundas das camadas populares e diversas, de onde venho, pois acredito que através das ações do feminismo jurídico, notadamente o de caráter popular, é possível estimular um processo de empoderamento social, político e jurídico dos sujeitos historicamente discriminados e excluídos, possibilitando não apenas uma apropriação consciente e engajada de determinados saberes e fazeres jurídicos por parte dos mesmos, mas o

Assim, fui talhando minha perspectiva que foi se aprimorando, pouco a pouco, e teve um maior aprimoramento após uma formação em "Incorporação da Perspectiva de Gênero ao Direito", realizada em Cuba. Em face disto, a Ordem dos Advogados do Brasil, subseção de Juazeiro do Norte, me outorgou uma comenda como forma estímulo e reconhecimento do trabalho desenvolvido. Atualmente, sou docente do Departamento de Gênero e Feminismo e ofereço, em nível de mestrado e doutorado, próprio aprofundamento e alargamento de sua cidadania, além de uma práxis jurídica mais democrática, horizontal e, sobretudo, sensível ao gênero e suas interseccionalidades.

\section{Da crítica feminista ao Direito à Teoria Feminista do Direito}

Durante anos os movimentos feministas olharam de modo crítico e desconfiado para o mundo jurídico, e com razão; pois este, através de um conjunto de instituições, normas, discursos e práticas, sempre legitimou a desigualdade de gênero, sustentando, inclusive de modo explícito, ideias de superioridade masculina e de inferioridade das mulheres (Facio, 1999; Barlett, 1991; Jaramillo, 2000; West, 2000; Facchi, 2005; Olsen, 2009; Rabenhorst, 2009).

a disciplina Gênero e Direito, além de outras correlatas, como Gênero e Poder, por exemplo. Todavia, entendo que o exercício do feminismo jurídico requer organização e ação coletiva, pois $\mathrm{o}$ processo de empoderamento jurídico das mulheres há que se construir socialmente, mormente através de políticas públicas e não somente por ações individuais, voluntárias e pontuais. Sigo servindo à sociedade através das ações de pesquisa e, sobretudo, extensionistas do Grupo JUSFEMINA. 
Como um produto da cultura, que ainda é hegemonicamente androcêntrica e sexista, as normas jurídicas serviram, e em grande medida ainda servem, para legitimar a exclusão social das mulheres e retardar o seu acesso à plena cidadania (Facio, 1999; Jaramillo, 2000). Em face disto, as relações entre feminismo e Direito sempre foram muito (in)tensas, uma vez que as feministas, ao longo da história, transitaram entre a denúncia, a reformulação, a desconstrução e o uso estratégico do saber/fazer jurídico, com vistas à garantia da igualdade de gênero (Emmenegger, 1999; Olsen, 2000; Jaramillo, 2000). Por isso, desde o seu nascedouro, no final do século XVIII, o feminismo vem denunciando o sexismo presente nas leis e no discurso jurídico, à época manifesto através da negação dos mais elementares direitos civis e políticos para as mulheres (Rubio, 2008).

Ao longo dos anos, no entanto, as opiniões feministas com relação a função e a utilidade do direito foram se diversificando e se tornando mais complexas, além de frequentemente discordantes, uma vez que, por conta das profundas mudanças e novas contradições sociais, o Direito ora era visto como mecanismo de dominação masculina, e ora era percebido como instrumento de aprimoramento da cidadania das mulheres, a depender do contexto histórico, do modo como elas entendiam sua opressão e da concepção que cada vertente ou onda do feminismo tinha ou tem do Direito e das relações que este estabelece com outras esferas da vida social (Jaramillo, 2000).

Visando compreender a situação mencionada, Carol Smart (1994), desenvolveu uma interessante classificação da percepção feminista do Direito, indicando o modo como os feminismos foram encarando o campo jurídico ao longo dos tempos. Com base na categorização desta autora, esta crítica feminista pode ser sintetizada em três correntes distintas que correspondem a três visões assim etiquetadas: o direito é sexista, o direito é masculino, o direito é sexuado. Cada uma destas percepções coincidem com uma das vertentes (ou ondas) do feminismo, conforme exponho no quadro abaixo para uma melhor compreensão do período e das estratégias utilizadas:

Quadro 2 - Percepções feministas do direito

\begin{tabular}{|c|c|c|}
\hline $\begin{array}{c}\text { O direito é } \\
\text { sexista }\end{array}$ & $\begin{array}{c}\text { O direito é } \\
\text { masculino }\end{array}$ & $\begin{array}{c}\text { O direito é } \\
\text { sexuado } \\
\text { (ou } \\
\text { gendrado) }\end{array}$ \\
\hline & & \\
\hline
\end{tabular}


Periódico do Núcleo de Estudos e Pesquisas sobre Gênero e Direito

Centro de Ciências Jurídicas - Universidade Federal da Paraíba

V. 8 - No 03 - Ano 2019

ISSN | 2179-7137 | http://periodicos.ufpb.br/ojs2/index.php/ged/index

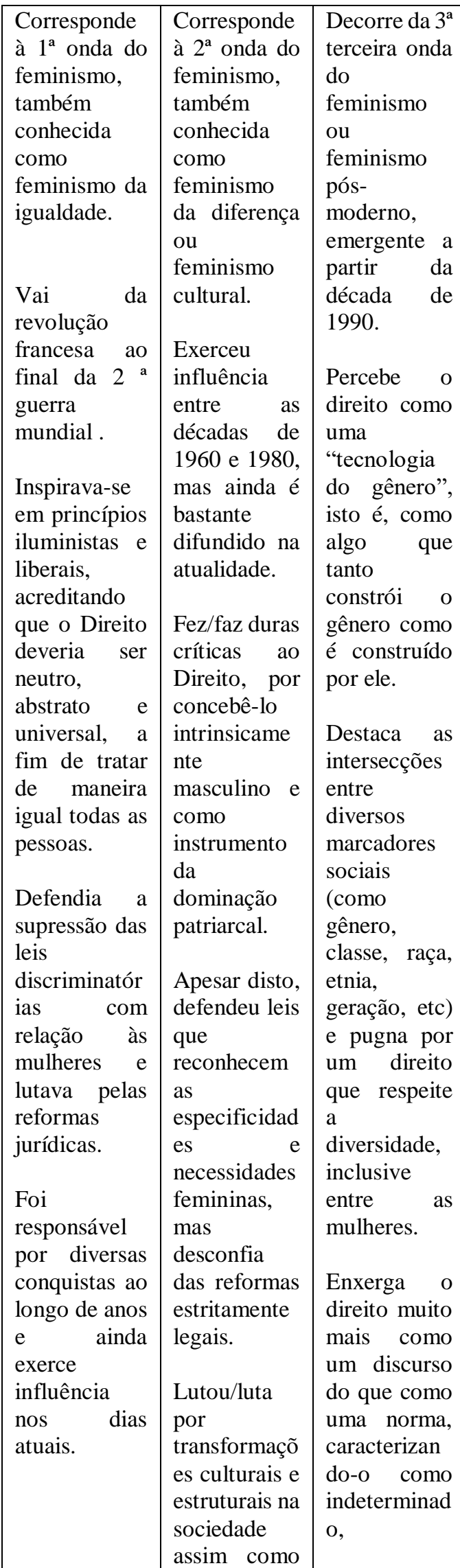

132

\begin{tabular}{|l|l|l|}
\hline & $\begin{array}{l}\text { no mundo } \\
\text { jurídico. }\end{array}$ & $\begin{array}{l}\text { inconsistente } \\
\text { e ambíguo. }\end{array}$ \\
\hline
\end{tabular}

Fonte: elaboração minha, baseada em SMART (1994)

Em face do exposto, a crítica feminista ao direito vai assumir múltiplas e diferentes perspectivas que, segundo Jaramillo (2000), coincidindo um pouco com Smart (1994), se manifesta de três modos específicos: a primeira problematiza a teoria do Direito propriamente dita (questionando os pressupostos do Direito e suas noções fundamentais), a segunda tece críticas a institutos jurídicos determinados (por entendê-los prejudiciais às mulheres ou mantenedores de sua subalternidade social), e a terceira põe em questão o modo como o direito é aplicado nos casos concretos, propondo usos estratégicos das leis ou interpretações inovadoras e emancipatórias das mesmas, além de novas metodologias de ensino, conforme o quadro a seguir, também delineado à luz das minhas leituras e reflexões sobre a obra da autora:

Quadro 1 - Tipos de crítica feminista ao direito

\begin{tabular}{|c|c|c|}
\hline $\begin{array}{c}\text { Crítica à } \\
\text { teoria do } \\
\text { Direito }\end{array}$ & $\begin{array}{c}\text { Crítica a } \\
\text { determinadas } \\
\text { instituições } \\
\text { jurídicas }\end{array}$ & $\begin{array}{c}\text { Crítica ao } \\
\text { modo como o } \\
\text { Direito é } \\
\text { aplicado }\end{array}$ \\
\hline $\begin{array}{l}\text { O direito é } \\
\text { produto das }\end{array}$ & $\begin{array}{l}\text { Questiona as } \\
\text { normas }\end{array}$ & $\begin{array}{l}\text { Refere-se à } \\
\text { aplicação do }\end{array}$ \\
\hline
\end{tabular}




\begin{tabular}{|c|c|c|}
\hline $\begin{array}{l}\text { Mesmo } \\
\text { quando } \\
\text { contempla } \\
\text { os } \\
\text { interesses } \\
\text { ou } \\
\text { demandas } \\
\text { das } \\
\text { mulheres, } \\
\text { continua } \\
\text { sendo } \\
\text { aplicado } \\
\text { por } \\
\text { instituições } \\
\text { e } \\
\text { profissiona } \\
\text { is } \\
\text { moldados } \\
\text { pela } \\
\text { ideologia } \\
\text { patriarcal. }\end{array}$ & $\begin{array}{l}\text { jurídicas que } \\
\text { excluem as } \\
\text { mulheres } \\
\text { como } \\
\text { destinatárias } \\
\text { de direitos } \\
\text { civis, } \\
\text { políticos, } \\
\text { sociais } \\
\text { econômicos } \\
\text { (com relação } \\
\text { ao voto, à } \\
\text { educação, ao } \\
\text { acesso } \\
\text { cargos a } \\
\text { empregos, à } \\
\text { plena } \\
\text { representação } \\
\text { política, à } \\
\text { seguridade } \\
\text { social, etc); } \\
\text { Discute as leis } \\
\text { que } \\
\text { criminalizam } \\
\text { o aborto. } \\
\text { Reflete sobre } \\
\text { os limites e } \\
\text { potencialidad } \\
\text { es das leis } \\
\text { referentes à } \\
\text { punição da } \\
\text { violência } \\
\text { doméstica, o } \\
\text { assédio sexual } \\
\text { e moral, etc. }\end{array}$ & 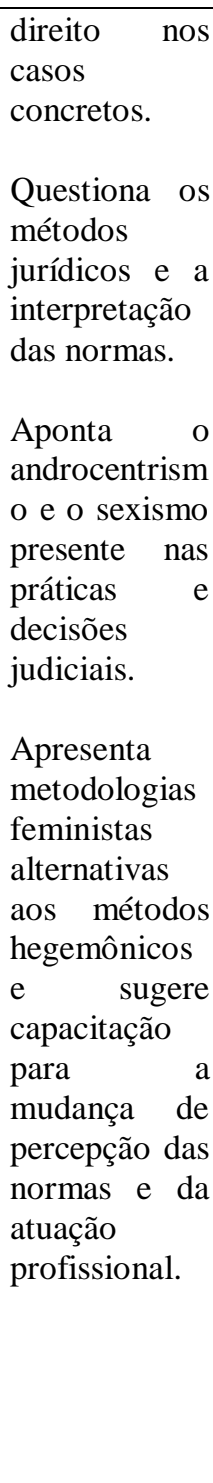 \\
\hline
\end{tabular}

Fonte: elaboração própria, baseada em Jaramillo (2000)

Como se pode ver, o feminismo, nas suas variadas versões, sempre se posicionou de forma crítica ao Direito, questionando, suspeitando e desvelando as categorias abstratas e pretensamente neutras com as quais este fenômeno costuma operar (Jaramillo, 2000; Chiarotti, 2006; Habenhorst, 2009). Apesar disto, nem todas as perspectivas feministas foram ou são completamente céticas com relação a este campo, pois a maioria delas, ao longo dos tempos, jamais deixou de apresentar propostas com vistas ao seu aprimoramento, haja vista que, em termos de direitos das mulheres, toda conquista jurídica corresponde a uma crítica, uma demanda, uma pressão e/ou mesmo uma proposição de caráter feminista, elaboradas de acordo com as condições e percepções feministas de cada época (Wilson, 2004; Rubio, 2008).

Assim, e apesar das contundentes críticas ao Direito realizadas ao longo da história, nem todas as perspectivas foram ou são completamente avessas ao mundo jurídico, afinal, como destaca Jaramillo (2000: 27, tradução minha), “o direito é uma das mais importantes ferramentas dentro da luta das mulheres por alcançar o lugar que desejam dentro da sociedade".

Por conta do exposto, muitas autoras sustentam que a gramática jurídica desempenha um papel importante na emancipação dos sujeitos subalternizados, razão porque advogam que não se deve simplesmente fechar os olhos para o campo jurídico ou seguir apenas criticando sem exercer qualquer influência sobre o mesmo (Facio, 1999; 
Wilson, 2004, Silva, 2018). E é justamente por apostar nesta visão que o feminismo foi se aproximado cada vez mais da seara jurídica, estabelecendo com esta uma relação de crítica mútua, mas também de importantes e exitosas parcerias. Destes encontros, emerge uma produção prolífera e profícua em termos de teorias, leis e metodologias jurídicas, perceptíveis através do exame acurado das produções científicas, legislativas e dos debates e ações jurídicas/jurisdicionais nos últimos tempos, inclusive no Brasil (Silva; Wiright, 2015).

Apesar do exposto, e conforme já pontuado, muitas autoras seguem chamando este conjunto de produções e intervenções jurídicas feministas de Teoria feminista do Direito ${ }^{6}$ ou de Pensamento jurídico feminista, o que, a meu sentir, não é de todo incorreto, mas, acredito eu, que essa ênfase exclusiva no aspecto teórico não dá conta da amplitude e da complexidade do

\footnotetext{
6 A "teoria feminista do direito", segundo Robin West (2000), seria um conjunto de reflexões teóricas, de base conceitual, que tem como propósito desmascarar e criticar o patriarcado oculto no arcabouço jurídico que apresenta uma teoria pretensamente neutra em relação ao gênero. Ou seja, visa desvelar o que podemos chamar de "teoria patriarcal do direito", encoberta pela proteção da teoria
}

fenômeno. Até porque, se por um lado o feminismo jurídico, como outras vertentes do feminismo, também necessita de produção teórica, tão importante para alimentar e orientar qualquer ação; por outro, a sua existência e consolidação exige muito mais do que uma sofisticada e criteriosa reflexão filosófica e/ou conceitual da realidade, pois envolve também a prática, ou melhor dizendo, a práxis jurídica, além de um conjunto de atividades destinadas ao compartilhamento e à socialização desta proposta transformadora que, conforme eu acredito, pode levar ao empoderamento jurídico de muitas mulheres, e sobre o qual tratarei no último tópico deste artigo. Por ora, vale perguntar: mas afinal, o que é esse tal de feminismo jurídico?

\section{Feminismo jurídico}

Não existe uma definição única e precisa do que venha a ser o feminismo jurídico. Todavia, pode-se dizer que há

do direito, que ainda se pretende pura. Para esta autora, o propósito primordial da crítica à teoria patriarcal do direito é mostrar que a teoria do direito e sua doutrina legal protegem e definem ao homem, não à mulher, que continua percebida como "o outro" da espécie humana ou, no dizer de Simone Beauvoir, como o "segundo sexo". 
um relativo consenso quanto à sua materialização, já que o mesmo se concretiza através da produção teórica, do educação jurídica (não necessariamente formal e acadêmica), da militância em favor da produção de leis mais inclusivas e não discriminatórias, e da atuação profisssional no âmbito do sistema de justiça (Silva, Wright, Nicácio, 2016; Silva, 2018).

Além disto, o feminismo jurídico, como qualquer outro tipo de feminismo, é marcado pela pluralidade, heterogeneidade e ausência de consensos (Facchi, 2005), o que lhe permite desenvolver diferentes abordagens,

\footnotetext{
${ }^{7}$ A exemplo do assistencialismo, a pessoa que compartilha uma visão salvacionista de mundo opera com absoluta convicção de que seu papel é de salvador/a de pessoas que não tem condições ou meios para fazer por si mesmas, e não se trata de prática de legítima defesa de terceiro, mas de iniciativas que visam substituir o outro, inclusive na fala, já que o/a salvador/a se considera detentor/a de qualidades excepcionais sem as quais $\mathrm{o}$ indivíduo a quem presta auxílio não teria condições de sobreviver ou de atuar em determinado contexto.

${ }^{8}$ Aqui reside a diferença entre as feministas que apenas fazem uso da lei para atuar numa causa, mostrar conhecimento e contribuir com o empoderamento de uma ou de algumas mulheres que elas consideram "clientes", independentemente do modo como o sistema de justiça opere ou do contexto social e econômico em que as relações de gênero se inserem; e as que consideram que o empoderamento individual é importante, sim, mas
}

perspectivas e propostas de intervenção, já que o pensamento feminista sobre o Direito não está imune às tensões decorrentes das hierarquias e assimetrias de classe, raça/etnia, orientações sexual, geração, territorialização, dentre outras, para além da própria desigualdade entre os gêneros e/ou intragenéricas, isto é, entre as próprias mulheres e os próprios homens. Eis porque, no meu entender, há que se diferenciar o feminismo jurídico puramente liberal, autocentrado, "salvacionista",, de cunho muitas vezes empresarial e voltado à "excelência profissional" em nome das mulheres, do feminismo jurídico $\operatorname{popular}^{8}$, vinculado

insuficiente para transformar as estruturas de poder e dominação, tais como o capitalismo, o racismo, o sexismo, o cisheteropartiarcado, dentre outros, no âmbito da quais o próprio Judiciário emerge e em cuja manutenção tem função primordial. Nesta última vertente, encontram-se as feministas jurídicas que não veem a lei ou o processo judicial como um fim em si mesmo, mas como um instrumento de disputa jurídica e política, buscando o transbordamento dos debates jurídicos para a esfera pública mais ampla, isto é, para a luta social, considerando os diversos sistemas de opressão e dominação que atuam de modo articulado e que andam de mãos dadas com o sexismo no seio do sistema de justiça, e em todas as instituições estatais. É neste campo que eu me situo desde longa data, pois é aqui onde a batalha não é por status pessoal ou profissional e muito menos por fama ou por prestígio. Trata-se de uma visão que exige ação coletiva e nada tem a ver exclusivamente com aparecer em 
aos movimentos sociais e à educação jurídica feminina, assim como de outros grupos historicamente discriminados e excluídos.

Conceitualmente, falando, podese dizer que o feminismo jurídico corresponde a um conjunto de críticas, teorizações, proposições metodológicas e atividades práticas desenvolvidas por juristas feministas ${ }^{9}$ em face do fenômeno jurídico, dentro ou fora do sistema de justiça. Afinal, a proposta central deste tipo de feminismo é desenvolver reflexões e sobretudo ações que promovam transformações radicais no âmbito das normas, discursos e práticas jurídicas, tendo como foco a obtenção da igualdade de gênero. $\mathrm{O}$ ponto de partida do feminismo jurídico é a percepção do caráter androcêntrico, porém cada vez mais ambíguo e enviesado do Direito, identificado como produto das sociedades patriarcais (Smart, 1994; Facio, 1999; Jaramillo, 2000).

Historicamente, é possível afirmar que o feminismo jurídico,

eventos ou apostar no estrelato. Tampouco há espaço para o culto à personalidades.

${ }^{9} \mathrm{Na}$ maioria das vezes em aliança com outros sujeitos de outras formações ou sem formação acadêmica alguma, posto que o importante aqui é a reflexão coletiva, horizontal e transformadora. enquanto produção teórica, vai surgir nos Estados Unidos ${ }^{10}$ durante a década de 1970, expandindo-se, sequencialmente, sobre a Europa e emergindo na América Latina nos anos 1990, com novos contornos e particularidades que vão ganhando força e utilidade nas lutas em defesa da cidadania e dos direitos humanos das mulheres, especialmente no contexto da redemocratização dos países deste eixo geográfico (Silva, Wright, 2015).

Do ponto de vista prático, o feminismo jurídico, enquanto produto e produtor da crítica feminista ao Direito, tem focado, dentre outros aspectos, no uso estratégico das leis, com vistas à construção da igualdade de gênero (Dahl, 1987; Rubio, 2008), pois passou da fase meramente denunciativa do sexismo jurídico para a teorização e ação concreta no âmbito do sistema de justiça (Wilson, 2004; Silva, 2018). Com base no exposto, o feminismo jurídico pode ser definido como uma espécie de ativismo jurídico que incorpora a

${ }^{10}$ Em chave decolonial, sustentamos que se faz necessário mais pesquisas e mais conhecimento acerca das experiências de outras sociedades e povos, especialmente a partir das noções de pluralismo jurídico. 
perspectiva de gênero no Direito, utilizando-se de estratégias políticas feministas para atuar neste campo, orientando demandas individuais ou coletivas e/ou auxiliando as lutas travadas na seara do Direito, dentro e fora do sistema de justiça ${ }^{11}$.

Como exemplo do referido ativismo jurídico, pode-se destacar diversas contribuições de juristas feministas envolvidas em mudanças legislativas ou em construção de políticas públicas destinadas a atender reivindicações das mulheres e/ou com recorte de gênero. A atuação de diversas juristas feministas no âmbito do lobby do batom, durante o processo Constituinte de 1987/88 no Brasil, é um bom exemplo a ser lembrado, pois em diversas ocasiões, dentro e fora da Assembleia Nacional Constituinte, a presença de feministas com formação em direito foi

\footnotetext{
${ }^{11} \mathrm{O}$ feminismo jurídico não se limita a atuar no âmbito do Poder Judiciário, embora este seja o locus privilegiado da petição de direitos. Muitas vezes a atuação das juristas feministas se dá na formação, na produção científica, na advocacia administrativa, na orientação jurídica de natureza preventiva em instituições governamentais e não governamentais, e em diversas outras instituições sociais. Muitas juristas feministas atuam em organismos nacionais e internacionais e em consórcios de entidades e/ou movimentos que fazem advocacy ou controle social das políticas públicas
}

de grande importância e utilidade, sobretudo nos debates em torno da questão do aborto, dos direitos das mulheres no âmbito da família, no mundo do trabalho e com relação à violência doméstica e intrafamiliar ${ }^{12}$ (Silva, 2012; Silva; Wright, 2015).

Em termos acadêmicos, vale mencionar a experiência pioneira de países anglo-saxônicos e escandinavos, durante a década de 1970, onde e quando foram criados os primeiros grupos de estudos sobre os direitos das mulheres. Merece destaque a iniciativa da Faculdade de Direito da Universidade de Oslo, na Noruega, que em 1974 instituiu uma disciplina denominada "jurisprudência feminista", por iniciativa da professora Tove Stang Dahl, autora do livro An Introduction to Feminist Jurisprudence ${ }^{13}$. Segundo esta autora:

O direito, enquanto instituição, contribui em grande medida

destinadas ao enfrentamento da violência contra a mulher ou outras demandas de interesse das mulheres em sua diversidade.

${ }^{12}$ Comba Marques Porto, Marília Muricy, Sílvia Pimentel, Florisa Verucci, dentre outras juristas feministas, contribuíram bastante com os debates que culminaram com a constitucionalização dos direitos das mulheres no Brasil.

${ }^{13}$ Esta obra foi publicada em inglês em 1987, sendo republicada, em português, em 1993 pela Fundação Calouste Gulbenkian, sediada em Lisboa. 
para a manutenção da tradicional hegemonia masculina na sociedade. Por outro lado, o direito é um terreno propício ao desenvolvimento de regras que podem dar origem a transformações importantes, inclusive na relação entre os dois sexos (Dahl, 1987: 7, tradução minha)

$\mathrm{Na}$ atualidade, em diversos países, e nas mais variadas Universidades do mundo, existem feministas jurídicas em ação, seja ministrando aulas, seminários, produzindo pesquisas e/ou realizando ações extra-universitárias, inclusive em parceria com outros tipos de feminismos. $\mathrm{Na}$ América Latina, um bom exemplo disto é a Red Latinoamericana de Académicas/os del Derecho ${ }^{14}$ que objetiva promover mudanças no ensino jurídico a partir da incorporação da perspectiva de gênero neste campo e da produção de novas medotologias com enfoque feminista.

No Brasil também há várias iniciativas em Universidades públicas e privadas situadas em diversas regiões. Para fugir um pouco do reforço à

\footnotetext{
${ }^{14}$ Dentre as brasileiras que fazem parte desta Rede podemos citar as seguintes docentes: Márcia Nina Bernardes, Ella Wieco, Salete Maria da Silva, Carmen Hein Campos,
}

geopolítica hegemônica do saber, que sempre põe em relevo o que acontece no centro econômico, político e cultural do país, vou destacar duas iniciativas desenvolvidas no nordeste brasileiro. A primeira delas está situada na Bahia: trata-se do grupo de pesquisa e ação em Gênero, Direito e Políticas para a Igualdade - JUSFEMINA, da Universidades Federal da Bahia, do qual sou coordenadora. A segunda, está situada no estado da Paraíba, e diz respeito ao grupo de extensão e pesquisa em gênero, educação popular e acesso à justiça, denominado MARIAS, da Universidade Federal da Paraíba, coordenado pela professora Tatyane Guimarães Oliveira. Nestes grupos, são realizadas atividades diversas voltadas para a disseminação e fortalecimento dos direitos humanos das mulheres, especialmente as das camadas populares, sempre com ações que favorecem o alargamento da cidadania feminina e a luta pela efetiva igualdade de gênero, sem olvidar as questões de raça, etnia, geração, sexualidade, dentre outras.

Eduardo Rabenhorst, dentre outras. Maiores informações no disponível em https://www.redalas.net/ 
Com relação à circulação da produção científica em termos de feminismo jurídico no Brasil, vale citar uma interessante revista denominada Gênero \& Direito, vinculada ao Centro de Ciências Jurídicas da Universidade Federal da Paraíba, com publicações de autoras/es nacionais e estrangeiras, também disponível no mundo virtual desde 2010. Outra experiência nortenordestina destinada ao compartilhamento da produção científica e de experiências práticas em termos de ativismo jurídico feminista, é o Grupo de Trabalho Gênero e Direito, criado em 2012 no âmbito do $18^{\circ}$ Encontro Nacional da Rede Feminista Norte e Nordeste de Estudos e Pesquisa sobre a Mulher e Relações de Gênero (REDOR),

${ }^{15} \mathrm{O}$ método de análise jurídica criado por Barlett propõe observar o seguinte: perguntar pelas mulheres diante de uma norma legal, partir das condições concretas de vida das mulheres para perceber o contexto em que se aplica, tomar consciência das relações de gênero antes de aplicar a norma.

${ }^{16}$ Além de Alda Facio, convém registrar outras autoras que tem contribuído muito em toda a América Latina para o desenvolvimento do que eu chamo de feminismo jurídico, tais como: Lorena Fries, Haydée Birgen, Cláudia Dominguez, Lourdes Enriquez, Lucia Raphael, Lília Ulloa Cuellar, Caroline Tovar, Malena Costa, Isabel Jaramillo, Carmen Hein Campos, Márcia Nina Bernardes, Ella Wieco, Adriana Mello, eu mesma, dentre do qual sou uma das proponentes e coordenadoras desde então.

Sobre metodologias jurídicas feministas, vale registrar que, além da pioneira contribuição de Katharine Barlett $^{15}$ (1991), merece destaque a proposta de Alda Facio (1999), já divulgada por outras autoras e também por mim em diversos textos e eventos (Silva, Wright, Silva Júnior,2018; Silva, 2018).

Com base nas contribuições de um vasto e destacado leque de autoras brasileiras e estrangeiras, especialmente latino-americanas ${ }^{16}$, sustento que o feminismo jurídico pode e deve desenvolver incidência política no âmbito do sistema de justiça, contribuindo, incialmente, para a

tantas outras juristas feministas com quem tenho estabelecido diálogos permanentes. Todas compõem um rol de pesquisadoras e ativistas que contribuem para $o$ desenvolvimento do feminismo jurídico nesta região. Outra autora que muito tem aportado para o desenvolvimento da perspectiva feminista no campo do direito é jurista negra norte americana Kimberle Crenshaw (2002), responsável pelo desenvolvimento do conceito de interseccionalidade, isto é, uma análise que requer a observação do cruzamento entre diversos fatores ou marcadores sociais que, ao se entrelaçarem, geram situações de desigualdades e/ou de discriminação ainda mais intensas para determinados grupos sociais, especialmente as mulheres. 
sensibilização das/os agentes e operadores deste campo e, posterior ou simultaneamente, para transformações estruturais mais profundas, em termos de relações de gênero, nestes espaços específicos. Vale pontuar que, de acordo com as reflexões desenvolvidas neste texto, bem como nossa experiência profissional no cenário da justiça, a incidência feminista pode ser realizada tanto no âmbito macro, isto é, em nível de Estado, mediante a construção das políticas públicas de administração da justiça, como no âmbito micro, ou específico de cada instituição, junto às/aos operadoras/es da justiça, através de ações e/ou recomendações que impactem as instituições ou modifiquem as pautas das/dos próprias/os operadoras/es.

Além disto, ações de apoio às mulheres em situação de violência, ou a seus representantes, visando fortalecer a

${ }^{17}$ Como a Convenção sobre a Eliminação de Todas as Formas de Discriminação contra a Mulher, de 1979, também chamada CEDAW (da sigla em inglês) e a Convenção de Belém do Pará, como ficou conhecida a Convenção Interamericana para Prevenir, Punir e Erradicar a Violência contra Mulher, adotada na referida cidade, em 9 de junho de 1994. É preciso que façamos mais controle de convencionalidade na realidade brasileira.

18 Trata-se de uma organização fundada em 1993 por advogadas e cientistas sociais exigibilidade de seus direitos, podem ser feitas com base nos marcos jurídicos internacionais ${ }^{17}$ e nacionais, dentre eles o próprio texto constitucional e as leis específicas relativas aos direitos das mulheres. Um exemplo de ação concreta bastante ilustrativo, é o trabalho pioneiro da organização não-governamental THEMIS, ${ }^{18}$ sediada no sul do país, e cujas ações e incidências jurídico-políticas são, além de inspiradoras, merecedoras de conhecimento, estudo e replicação por todas as pessoas que desejem enveredar pelo campo da práxis jurídico-feminista, até porque, trata-se, precisamente, de ações que conduzem ao que eu chamo de empoderamento jurídico das mulheres, sobre o que tratarei neste último item.

\section{Empoderamento jurídico feminino}

Do feminismo jurídico, notadamente o de caráter popular,

feministas, sediada na cidade de Porto Alegre-RS, que tem como objetivo enfrentar a discriminação contra as mulheres no Sistema de Justiça. Um dos projetos mais importantes desta ONG é o "Promotaras Legais Populares", que visa capacitar mulheres em temas relacionados aos seus direitos e ao funcionamento do Sistema de Justiça, a fim de que possam, elas próprias, acompanhar suas demandas e monitorar as políticas públicas. Para saber mais, acesse http://themis.org.br/somos/historia/ 
resultam ações e experiências que geram empoderamento jurídico para as mulheres, ou empoderamento jurídico feminino, como eu costumo falar. $\mathrm{O}$ empoderamento jurídico, de um modo geral, pode ser entendido como um subproduto adjetivado do termo empoderamento que, por sua vez, costuma ser definido como um processo de tomada de consciência e de organização social destinado à superação de barreiras políticas, econômicas, culturais, dentre outras, por meio do qual são desenvolvidas determinadas habilidades e competências que possibilitam a aquisição, o usufruto, o compartilhamento e o controle de determinados bens, serviços, direitos, espaços etc (Crespo, s/d).

O conceito de empoderamento, tomado em perspectiva feminista, envolve distribuição de poder entre os sujeitos sociais e tem como foco as ideias de acesso e controle de recursos materiais e imateriais historicamente negados (León, 2000; Townsend, 2002; Sardenberg, 2012). De todo modo, o empoderamento, como se sabe, nunca é unidimensional. Por isso, falar em empoderamento político, social, econômico ou jurídico de maneira isolada pode gerar incompreensões ou ilusões nos sujeitos sociais, além de dar a sensação de que é suficiente focar em algum aspecto da luta por melhores condições de vida. Todavia, quando se trata de grupos socialmente discriminados ou excluídos, a depender do contexto e das questões que estão em jogo, pode-se pensar em construir mecanismos que possibilitem a ênfase em determinado aspecto, mas somente durante determinado período, valendo pontuar que o que vai definir esta opção é a realidade concreta e o ponto de vista dos atores envolvidos (pessoas, grupos, organizações, governos etc.).

$\mathrm{O}$ foco no aspecto jurídico do empoderamento, tratado por mim neste tópico, tem sua razão de ser em face do que apontam diversas pesquisas sobre gênero e acesso à justiça, inclusive as realizadas pelo grupo que coordeno na UFBA (Silva et al., 2016). Tais pesquisas revelam um frequente desconhecimento por parte das mulheres, especialmente as das camadas populares, com relação aos seus direitos e a toda dinâmica estatal em torno dos mesmos, notadamente o sistema de justiça; o que gera descrença e impotência naquelas que acorrem ao Judiciário, por se tratar de um espaço que opera com instrumentos sobre os quais 
elas tem pouco ou nenhuma familiaridade.

De toda sorte, o empoderamento, seja ele de que natureza for, não é algo que se outorga a alguém, posto que é construído pelos próprios sujeitos sociais que o almejam. Porém, pode ser facilitado ou induzido por meio de ações que aprofundem a compreensão e a participação cidadã, assim como por medidas que favoreçam o desenvolvimento de capacidades e habilidades específicas, além da construção de atividades, alianças e redes que possibilitem o fortalecimento individual e coletivo dos sujeitos e de seus movimentos sociais (Kabeer, 1999; Townsend, 2002).

Diante disto, o empoderamento jurídico tem sido definido de diferentes formas, sendo que todas elas enfatizam ideias como conhecimento, apropriação, participação, poder, compartilhamento, inclusão, dentre outras. Segundo Luís Roberto Barroso,

Empoderamento jurídico é a possibilidade efetiva de fazer valer os próprios direitos. Tal possibilidade depende de consciência de cidadania, informação e meios de atuação,

19 Este evento foi promovido pela Red Global de Empoderamiento Jurídico. $\mathrm{Na}$ ocasião, foi elaborada a Declaración de Villa Inflamable, disponível em não necessariamente judiciais. $\mathrm{O}$ acesso à justiça, por sua vez, envolve a possibilidade, sobretudo das pessoas mais pobres, de levar sua demanda a um tribunal, mesmo que ela não seja expressiva economicamente, à luz dos padrões usuais. Para tanto, é preciso, além do empoderamento legal, isenção de custos ou custos baixos e assistência judiciária para quem não tem recursos para pagar um advogado privado ( Barroso, 2014: 2-3):

O entendimento acima é corroborado por mim, assim como por diversos ativistas, como se pode ver das falas de alguns participantes do Seminário "Perspectivas sobre Empoderamiento Juridico: Intercambio Regional de Aprendizagen en América Latina", ocorrido em Buenos Aires, em $2017^{19}$ :

É o processo através do qual as pessoas se apropriam das leis, dos mecanismos que existem para alcançar seus direitos, desenvolvendo reconhecimento do seu poder pessoal e de si próprios como sujeitos de direitos (Laura Spinoza, Chile. Tradução e grifo meu)

É dar as ferramentas e as capacidades às pessoas das comunidades e aos grupos vulneráveis para que possam

http://www.fima.cl/wordpress/2017/06/29 /declaracion-de-villa-inflamable-por-elacceso-a-la-justicia-para-todasos-y-elempoderamiento-juridico/ 
por si mesmos e por si mesmas serem capazes de desenvolver processos de exigibilidade de direitos (Jorge Acero, Equador. Tradução e grifo meu).

É poder acessar à Justiça, não vista somente como um tribunal, mas como um serviço e ter possibilidade de viver como um ser humano com dignidade (Ruben Ninahuana, Peru. Tradução e grifo meu).

É a forma como que as pessoas que foram vulnerabilizadas em seus direitos podem reapropriar-se da linguagem jurídica e transformar suas próprias realidades (César León, México. Tradução e grifo meu).

De acordo com tais afirmações, vê-se que a ideia de empoderamento jurídico envolve processos de participação coletiva, reflexão crítica e desenvolvimento de habilidades e competências que potencializam o exercício da cidadania e das lutas por direitos humanos, dentre as quais se inserem as demandas por acesso à justiça. Assim sendo, as estratégias de empoderamento jurídico fazem parte de um campo de atuação política e social que foca na educação e na prática dos direitos humanos, pois considera as experiências das comunidades e dos grupos sociais historicamente discriminados e afetados pelas injustiças a fim de reverter esta situação, fortalecendo suas capacidades de conhecer, usar a lei e o Direito para encontrar soluções aos seus problemas. Mas sempre com plena consciência dos limites e até mesmo armadilhas destas ferramentas.

Tais ações, em regra, coadunam com a perspectiva do feminismo jurídico, notadamente o popular, cujas ações e reflexões se desenvolvem em perfeita sintonia com as lutas sociais das mulheres das camadas menos favorecidas da sociedade. Este tipo de feminismo não visa apenas atuar por atuar, mas possibilitar os meios para que os próprios sujeitos possam ter agência na construção, apresentação e acompanhamento de suas demandas.

Vale pontuar que no mundo inteiro existem várias organizações trabalhando com processos de empoderamento de grupos historicamente discriminados e excluídos, no âmbito das quais nem sempre aparecem os debates sobre empoderamento jurídico. Apesar disso, há diversos outros movimentos $\mathrm{e}$ entidades civis onde a temática tem sido objeto de reflexões e ações baseadas em propostas de uso estratégico do Direito e 
de acesso coletivo ao sistema de justiça $^{20}$. Muitas das iniciativas visam construir práticas e discursos emancipatórios e colaborativos capazes de auxiliar os grupos sociais no acesso e na produção de conhecimentos $\mathrm{e}$ ferramentas que lhes permitam não apenas inovar na incidência política e jurídica, mas fazê-lo de modo mais efetivo nas variadas instâncias e estruturas estatais.

No Brasil, conforme já mencionado, há interessantes e inspiradoras experiências de ações voltadas ao empoderamento jurídico das mulheres, a exemplo do Projeto denominado Promotoras Legais Populares (PLP), um dos mais conhecidos sobre a temática, que tem sido desenvolvido por entidades da sociedade civil e por universidades como

$20 \mathrm{Na}$ América Latina podemos destacar algumas experiências de empoderamento jurídico, tais como: as ações da Fundação Construir, sediada na Bolívia, que atua fortalecendo mulheres para que se tornem defensora comunitárias organizadas em prol do direito a uma vida livre de violência; as ações da ONG TECHO, que atua em diversos países dessa região em prol do direito à moradia; o trabalho do Grupo de Monitoramento Independente de El Salvador-GMIES, que promove e defende direitos trabalhistas para trabalhadores e trabalhadoras que estão em situação de atividade de extensão, em sua maioria no sul e sudeste do país (Oliveira, 2013).

Para citar, mais uma vez, o nordeste brasileiro, eu destacaria mais duas iniciativas realizadas fora das Universidades, embora em diálogo com estas, que, a meu sentir, são voltadas ao empoderamento jurídico das mulheres. E, ainda que não adotem, de modo explícito e expresso, a nomenclatura feminismo jurídico para se referir a suas ações, ou o termo empoderamento jurídico feminino para nomear seus objetivos, o fatoé que estão atuando precisamente nesse sentido, tais como os trabalhos realizados pela ONG "Tamos juntas"21, sediada em Salvador, Bahia, e que desenvolve palestras, oficinas e ações voltas ao acompanhamento jurídico de mulheres em situações de violência doméstica e familiar; e as atividades do Grupo de Atuação Especial em Defesa da Mulher-GEDEM ${ }^{22}$, vinculado ao Ministério Público

vulnerabilidade e exclusão social, focando, principalmente, em mulheres, jovens, migrantes, pessoas com deficiência, indígenas e refugiados, dentre outros. Vide a Rede Global de Empoderamento Jurídico, conhecida como Namati (2018), Esta rede reúne mais de 1400 organizações e mais de 5 mil pessoas. Maiores informações podem ser encontradas em www.namati.org/join

${ }^{21} \mathrm{Cf}$. https://tamojuntas.org.br/ 22

Cf. https://www.mpba.mp.br/area/caodh/grup osatuacaoespecial/gedem 
estadual, que tem desenvolvido ações de capacitação com profissionais das redes de enfrentamento à violência de gênero e diálogos com os movimentos de mulheres sobre seus direitos.

Além das mencionadas experiências, existem muitas outras iniciativas, neste e noutros estados da federação, que podem ser caracterizadas como ações que facilitam o empoderamento jurídico das mulheres, porém nem todas adotam ou assumem as estratégias de empoderamento jurídico no sentido em que estou tratando neste texto. Ademais, a quase totalidade das iniciativas, postas em prática de norte a sul do Brasil, não constituem políticas públicas especificamente geradas para este fim. E neste particular, gostaria de fazer um parênteses, pois reside precisamente aqui uma questão sobre a qual tenho me debruçado bastante nos últimos três anos, qual seja: a necessidade de elaboração de políticas públicas voltadas ao empoderamento jurídico feminino, uma vez que é dever

${ }^{23}$ Vale pontuar que a Agenda 2030 para o Desenvolvimento Sustentável, da qual o Brasil é subscritor, apresenta como prioridade o apoio ao acesso sustentável das mulheres à Justiça, por meio das metas apresentadas pelo Objetivo 5, das quais emerge o compromisso de "adotar e do Estado garantir as condições mínimas de acesso pleno à cidadania para as mulheres e meninas, já que assumimos compromissos, inclusive internacional, neste sentido ${ }^{23}$.

Ademais, é importante e necessário que todas as mulheres conheçam minimamente o direito vigente em seu país, bem como as normas que os proclamam e as instituições e instâncias que os protegem e garantem. Sendo, contudo, mais importante ainda, que elas possam intervir, falar, questionar, contribuir na formulação, monitoramento e avaliação dos mesmos, ou seja, protagonizar suas próprias demandas e questões que lhes afetam em espaços específicos, como o sistema de justiça, por exemplo. Mas este é o tema de outro artigo da lavra do grupo Jusfemina que está em iminente publicação.

\section{Considerações finais}

As relações entre feminismo e Direito nunca foram totalmente

fortalecer políticas sólidas e legislação aplicável para a promoção da igualdade de gênero e o empoderamento de todas as mulheres e meninas, em todos os níveis" (grifo meu). Disponível em http://www.agenda2030.com.br/ 
tranquilas, mas sempre foram necessárias, uma vez que ambos trabalham com as ideias de igualdade, dignidade, liberdade, cidadania e de justiça social, ainda que em perspectivas diferentes e, em muitos casos, diametralmente opostas.

Desde a Revolução Francesa, com o surgimento da primeira onda do feminismo, até os dias atuais, feministas tem desenvolvido diversas e profícuas críticas ao Direito, enquanto sistema de normas destinadas à regulação da vida em sociedade. Estas críticas, todavia, não se dirigem apenas às leis, mas aos discursos, às práticas e à linguagem do Direito, dado seu caráter hermético, elitista, racista e marcadamente androcêntrico.

O feminismo jurídico, através de suas críticas e proposições teóricas, políticas e jurídicas, tem legado, não somente às mulheres, mas à sociedade como um todo, uma grande quantidade de conquistas nas diversas áreas da vida social. Estas conquistas podem ser notadas através da ampliação dos direitos das mulheres, da incorporação legal de suas demandas e necessidades específicas e da paulatina expansão e fortalecimento da cidadania feminina, inclusive no Sistema de Justiça.
Além das críticas e teorizações, o feminismo jurídico apresenta também metodologias destinadas ao uso estratégico do direito, cuja finalidade é proporcionar um "olhar gendrado" sobre o fenômeno jurídico e uma mudança de mentalidade e de ação na seara do direito e no sistema de justiça como um todo.

Apesar do exposto, o feminismo jurídico ainda é pouco conhecido no Brasil, merecendo ser divulgado e apropriado por tantas/os quantas/os desejem contribuir para uma efetiva transformação nas relações de gênero em nosso país. Este texto, portanto, objetivou facilitar a introdução ao feminismo jurídico, gerando interesse pela temática e estímulo para outras e aprofundadas leituras.

Além disto, este artigo também buscou pontuar a importância do empoderamento jurídico feminino, como resultado das ações do feminismo jurídico, notadamente o de caráter popular. Deixou claro, portanto, que tal empoderamento, enquanto processo de aquisição de consciência, de poder de fala, de apropriação de conteúdos de normas e/ou de ferramentas jurídicas, visa a ampliação e o fortalecimento da cidadania feminina, haja vista que favorece a exigibilidade de direitos e a 
defesa de seus interesses, necessidades e desejos, ainda que estejam legal e suficientemente representadas por profissionais do Direito.

Assim, se o empoderar-se envolve a possibilidade de tomar controle de suas próprias vidas, no sentido mais amplo desta expressão, empoderar-se juridicamente envolve a possibilidade de não se deixar controlar, substituir ou colonizar-se por nenhum sujeito, ator ou instituição, por mais boa vontade que estes efetivamente tenham ou aleguem ter.

\section{Referências bibliográficas}

Bandeira, Lourdes. A contribuição da crítica feminista à ciência. Estudos Feministas. Florianópolis, 16(1): 288, janeiro-abril/2008. Disponível em https://periodicos.ufsc.br/index.php/ref/artic le/view/S0104026X2008000100020/553

Barroso, Luís Roberto. Justiça, empoderamento jurídico e direitos fundamentais. Disponível em: http://www.luisrobertobarroso.com.br/wpco ntent/uploads/2014/06/ONU Justica-

Empoderamento-legal-e-direitosfundamentais versao-em-portugues.pdf. Barlett, Katharine T. Feminist legal methods. In Barlett, Katharine T.
Kennedy, Rosanne. Feminist legal theory. Colorado: Westview Press, 1991, p.370-403.

Campos, Carmen Hein. Teoria Feminista do Direito e Violência Ín• ma Contra Mulheres R. EMERJ, Rio de Janeiro, v. 15, n. 57 (Edição Especial), p. 33-42, jan.-mar. 2012. Disponível em http://www.emerj.tjrj.jus.br/revistaemerj_o nline/edicoes/revista57/revista57 33.pdf Chiarotti, Susana. Aportes al Derecho desde la Teoría de Género. Revista Otras Miradas. Colombia: Universidad de Los Andes, v. 6, n. 1, junio/2006, pp. 6-23.

Costa, Ana Alice A. $O$ movimento feminista no Brasil: dinâmicas de uma intervenção política. Revista Gênero, 2005. Disponível em http://www.revistagenero.uff.br/index.php/r evistagenero/article/view/380/285

Costa, Malena. El Pensamiento Jurídico feminista en América Latina. Escenarios, contenidos y dilemas. Revista Gênero e Direito. Centro de Ciências Jurídicas/ UFPB. $\mathrm{N}^{\mathrm{o}} 02-2^{\circ}$ Semestre de 2014, pp. 11-34.

Crenshaw, Kimberle. Documento para o encontro de especialistas em aspectos da 
discriminação racial relativos a gênero.

2002. [online]. Disponível em

http://www.scielo.br/pdf/ref/v10n1/116

36.pdr.

Crespo, Patrício (coord.).

Empoderamiento. ¿Tomar las riendas?

Ecuador: Servicio de Gestión del

Conocimiento para Latinoamérica y el

Caribe. S/d.

Dahl, Tove Stang. An Introduction to feminist jurisprudence. Oslo: Universitetsfortaleg AS, 1987.

Emmenegger, Susan. Perspectivas de género en derecho. 1999. [online] Disponível

em

https://www.unifr.ch/ddp1/derechopenal/anuari o/an_1999 05.pdf.

Facchi, Alessandra. El pensamiento feminista sobre el derecho: un recorrido desde Carol Gilligan a Tove Stang Dohl. Academia. Revista sobre enseñanza del derecho de Buenos Aires, Año 3, Nro. 6 (primavera 2005), p. 27- 47.

Facio, Alda. Cuando el género suena cambios trae (una metodología para el análisis de género del fenómeno legal. San José, C.R.: ILANUD, 1999a.
Facio, Alda; Fries, Lorena. Género y Derecho. Santiago de Chile, LOM, 1999b.

Jaramillo, Isabel Cristina. La crítica feminista al derecho. In: WEST, Robin. Género y teoria del derecho. Bogotá, Siglo del Hombre Editores, 2000.

Kabber N. Ressources, Agency, Achievements: Reflections on the Measurement of Women's Empowerment. 1999. Disponível em: https://www.utsc.utoronto.ca/ kmacd/I DSC10/Readings/research\%20design/e mpowerment.pdf

Leon, Magdalena. Empoderamiento: relaciones de las mujeres con el poder. Disponível em: http://conlaa.com/wpcontent/uploads/2017/07/52-fondo-de-

biblioteca- articulo.pdf.

Lerussi, Romina Carla; Costa, Malena. Los feminismos jurídicos en Argentina. Notas para pensar un campo emergente. Disponível em http://www.scielo.br/pdf/ref/v26n1/180 6-9584-ref-26-01-e41972.pdf

Oliveira, Julia Glaciela. Promotoras legais populares: a construção de pontes para a cidadania feminina. Serv. Soc. 
Rev., londrina, v. 15, n. 2, p. 5-27, jan./jun. 2013.

Olsen, Frances. El sexo del derecho. In: Ruiz, A. (comp.) Identidad femenina y discurso jurídico. Buenos Aires: Biblos, 2000, p. 1-19.

Pitch, Tamar. Sexo y género de y en el derecho: el feminismo jurídico. Anales de la Cátedra Francisco Suárez, 44 (2010), 435-459. Disponível em http://revistaseug.ugr.es/index.php/acfs/arti cle/view/515/605

Rabernhorst, Eduardo. $O$ feminismo como crítica do direito. Revista Eletrônica Direito e Política, Programa de Pós-Graduação stricto sensu em Ciência Jurídica da UNIVALI, Itajaí, v. 4, n. 3, $3^{\text {o }}$ quadrimestre de 2009. Disponível em

www.univali.br/direitoepolítica.

Rubio, Aratanza Campos. Aportaciones iusfeministas a la revisión crítica del derecho y a la experiencia jurídica. In: Mujeres y derecho: pasado y presente. I Congreso multidisciplinar de la sesión de Bizkaia de la Facultad de Derecho. Octubre de 2008.

Sardenberg, Cecília. Conceituando o empoderamento na perspectiva feminista. Disponível em: https://repositorio.ufba.br/ri/bitstream/ri /6848/1/Conceituando\%20Empoderame nto\%20na\%20Perspectiva\%20Feminist a.pdf

Silva, Salete Maria da. Constitucionalização dos direitos das mulheres no Brasil: um desafio à incorporação da perspectiva de gênero no Direito. Disponível em https://periodicos.set.edu.br/index.php/d ireito/article/view/178/76

Silva, Salete Maria da; Wright, Sonia Jay. As mulheres $e$ o novo constitucionalismo: uma narrativa feminista sobre a experiência brasileira. 2015. [online] Disponível em http://www.conpedi.org.br/publicacoes/ 66fsl345/gv4u3hv2/i3jf3jt72swcdyoi.pd f.

Silva, Salete Maria da; Wright, Sonia Jay; Nicácio, Jeferson. Feminismo jurídico latino americano: a relevante contribuição teórica de Alda Facio. In: Anais do $19^{\circ}$ REDOR, Universidade Federal de Sergipe - Aracaju-SE, 15-17 junho, 2016. 
Silva, Salete Maria da; Santos, Ana Lúcia; Nicácio, Jeferson; Oliveira, Angélica. Fala Maria Porque é de Lei: a percepção das mulheres sobre a implementação da lei Maria da Penha em Salvador/BA. Disponível em https://www.researchgate.net/publication/33 0356470_FALA_MARIA_PORQUE_E_D E_LEI_a_percepcao_das_mulheres_sobre a_implementacao_da_lei_Maria_da_Penha _em_SalvadorBA

Silva, Salete Maria da. Feminismo Jurídico: uma introdução. Disponível em:

https://portalseer.ufba.br/index.php/cad gendiv/article/view/25806

Silva, Salete Maria da; Wright, Sonia Jay; Silva Júnior, Enézio. A interface entre Gênero e Direito: entrevista com Alda Facio. Disponível em https://portalseer.ufba.br/index.php/c adgendiv/article/view/25839/0 Smart, Carol. La teoría feminista y el discurso jurídico. In Larrauri, Elena (Comp.). Mujeres, Derecho penal y criminología. Madri: Siglo Veintiuno, 1994, p.167-189.

Townsend, Janet Gabriel. Contenido del empoderamiento: como entender el poder. In: Zapata-Martelo, Emma et al (org.). Las mujeres y el poder: contra el patriarcado y la pobreza. México: Plaza y Valdes Editores, 2002.

Tovar, Carolina V. El concepto de justicia de género: teorías y modos de uso. Revista de Derecho Privado, n. ${ }^{\circ} 21$, julio-diciembre de 2011, pp 119-146.

Weste, Robin. Género y teoria del derecho. In: West, Robin (org.) Género y teoria del derecho. Bogotá, Siglo del Hombre Editores, 2000.

Wilson, Mariblanca Staff. La perspectiva de género en el derecho. In: Calderón, Rosaura Chinchilla. Pensamiento jurídico feminista. Desconstruir el derecho, repensar el mundo. San José, C.R.: IJSA, nov. 2004, pp. 55-68 